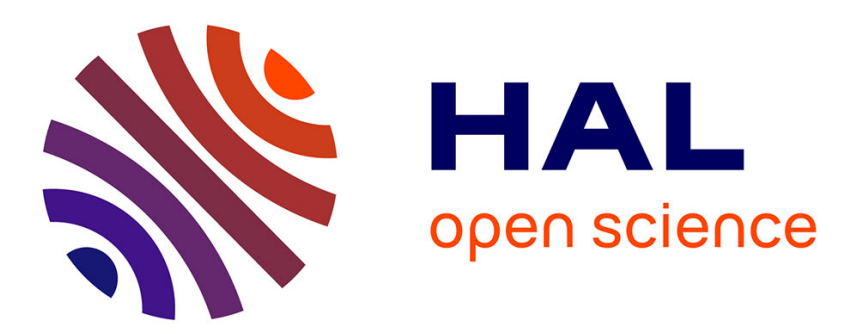

\title{
Plastic Instability Based on Bifurcation Analysis: Effect of Hardening and Gurson Damage Parameters on Strain Localization
}

\author{
Lotfi Mansouri, Hocine Chalal, Farid Abed-Meraim, Tudor Balan
}

\section{- To cite this version:}

Lotfi Mansouri, Hocine Chalal, Farid Abed-Meraim, Tudor Balan. Plastic Instability Based on Bifurcation Analysis: Effect of Hardening and Gurson Damage Parameters on Strain Localization. Key Engineering Materials, 2012, 504-506, pp.35-40. 10.4028/www.scientific.net/KEM.504-506.35 . hal01200489

\section{HAL Id: hal-01200489 \\ https://hal.science/hal-01200489}

Submitted on 24 Jun 2016

HAL is a multi-disciplinary open access archive for the deposit and dissemination of scientific research documents, whether they are published or not. The documents may come from teaching and research institutions in France or abroad, or from public or private research centers.
L'archive ouverte pluridisciplinaire HAL, est destinée au dépôt et à la diffusion de documents scientifiques de niveau recherche, publiés ou non, émanant des établissements d'enseignement et de recherche français ou étrangers, des laboratoires publics ou privés. 


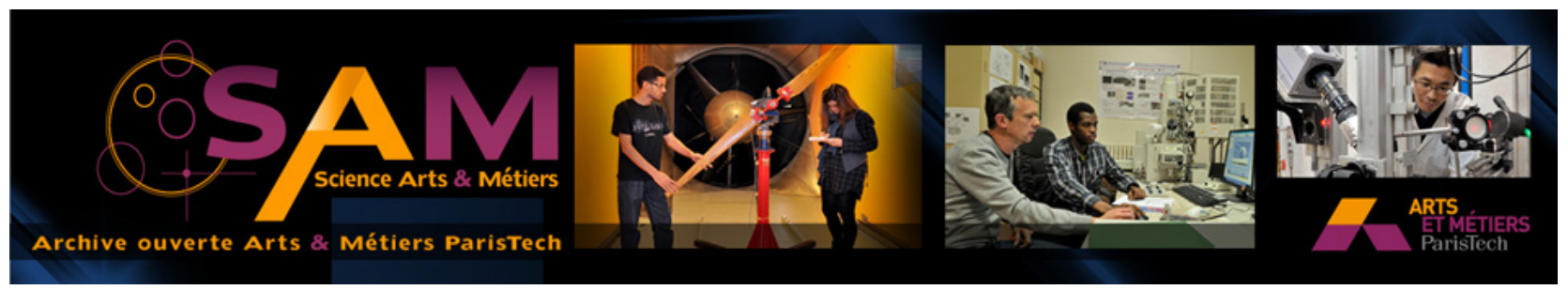

\section{Science Arts \& Métiers (SAM)}

is an open access repository that collects the work of Arts et Métiers ParisTech researchers and makes it freely available over the web where possible.

This is an author-deposited version published in: http://sam.ensam.eu

Handle ID: .http://hdl.handle.net/null

\section{To cite this version :}

Lotfi MANSOURI, Hocine CHALAL, Farid ABED-MERAIM, Tudor BALAN - Plastic Instability Based on Bifurcation Analysis: Effect of Hardening and Gurson Damage Parameters on Strain Localization - Key Engineering Materials - Vol. 504-506, p.35-40 - 2012 


\title{
Plastic Instability Based on Bifurcation Analysis: Effect of Hardening and Gurson Damage Parameters on Strain Localization
}

\author{
Lotfi Zoher MANSOURI ${ }^{a}$, Hocine CHALAL $^{\mathrm{b}}$, Farid ABED-MERAIM ${ }^{\mathrm{c}}$ \\ and Tudor BALAN ${ }^{d}$
}

\author{
LEM3, UMR CNRS 7239, Arts et Métiers ParisTech 4, rue Augustin Fresnel, 57078 \\ Metz Cedex 03, France \\ aLotfi-Zoher.MANSOURI-7@etudiants.ensam.eu, ${ }^{\mathrm{b}}$ hocine.chalal@metz.ensam.fr, \\ 'farid.abed-meraim@ensam.eu, dudor.balan@ensam.eu
}

\begin{abstract}
Keywords: Finite Elasto-Plasticity, Damage, Strain Localization, Sheet Metal Forming, Forming Limit Diagram.
\end{abstract}

\begin{abstract}
In this work, we propose to couple the Gurson-Tvergaard-Needleman (GTN) model, known for its widespread use to describe damage evolution in metallic materials, to the Rice localization criterion. The implementation of the constitutive modeling is achieved via a user material (UMAT) subroutine in the commercial finite element code ABAQUS. Large deformations are taken into account within a three dimensional co-rotational framework. The effectiveness of the proposed coupling for the prediction of the formability of stretched metal sheets is shown and Forming Limit Diagrams (FLDs) are plotted for an Aluminum alloy. A sensitivity analysis with respect to hardening parameters is carried out, and it is shown that these effects are much smaller for the case of the Rice criterion when compared to classical criteria commonly utilized in metal forming.
\end{abstract}

\section{Introduction}

Since the pioneering work of Keeler [1], forming limit curves are still a powerful concept for characterizing ductility of sheet metals subjected to forming operations. This concept was originally based upon an experimental approach involving metal sheets of different geometries in order to scan a certain range of loading paths. However, the experimental approach is expensive and time consuming. For these reasons, many researchers became interested in the prediction of forming limit curves by theoretical approaches. Two ingredients are necessary to achieve this end. On one hand, a constitutive law is needed to reproduce the material response to a given loading path and, on the other hand, a localization criterion is introduced to detect the occurrence of plastic instabilities. In the current work, the formability limits of metal sheets are investigated by means of GTN-Rice [2-4] modeling taking into account damage evolution by void nucleation, growth and coalescence. The paper is organized as follows: first, we give a brief recall of the GTN model including the expression of the elasto-plastic tangent modulus, and then the expression of the acoustic tensor is derived within a finite strain framework. In the results and discussion section, we show the effectiveness of the proposed modeling for the prediction of forming limit diagrams (FLDs) including a sensitivity analysis to the hardening parameters. Finally, some concluding remarks are drawn as well as some directions for future work.

\section{Constitutive model}

The GTN model is probably one of the most popular damage models for the prediction of the ductile fracture. This model was originally proposed by Gurson [2] to describe nucleation and growth of voids in a finite medium and was extended in a phenomenological manner by Needleman and Tvergaard [3] to better fit experimental results. This macroscopic yield function is given by the following relation: 


$$
\Phi=\left(\frac{\Sigma_{e q}}{\bar{\sigma}}\right)^{2}+2 q_{1} f^{*} \operatorname{ch}\left(\frac{3}{2} \frac{q_{2} \Sigma_{m}}{\bar{\sigma}}\right)-\left(1+q_{3} f^{* 2}\right) \leq 0,
$$

where $\Sigma_{e q}=\left(3 / 2 \Sigma^{\prime}: \Sigma^{\prime}\right)^{1 / 2}$ and $\Sigma_{m}=\operatorname{tr}(\Sigma) / 3$ represent, respectively, the macroscopic equivalent stress and the macroscopic average stress. $\bar{\sigma}$ is the yield stress of the fully dense matrix; here only isotropic hardening is considered using a Swift law defined as follows:

$$
\bar{\sigma}=k\left(\varepsilon_{0}+\bar{\varepsilon}^{p}\right)^{n}
$$

where $k, \varepsilon_{0}$ and $n$ are parameters of the Swift hardening law and $\bar{\varepsilon}^{p}$ is the equivalent plastic strain of the matrix material. $q_{1}, q_{2}$ and $q_{3}$ are the Tvergaard parameters and $f^{*}$ represents the effective porosity, which will be defined hereafter. The plastic part $\mathbf{D}^{p}$ of the macroscopic strain rate and the rate of equivalent plastic strain $\dot{\bar{\varepsilon}}^{p}$ are assumed to be related by the equivalent plastic work expression as follows:

$$
(1-f) \bar{\sigma} \dot{\bar{\varepsilon}}^{p}=\Sigma: \mathbf{D}^{p}
$$

where $f$ represents the porosity and $\Sigma$ the macroscopic Cauchy stress tensor. We also define the expression of the plastic strain rate as follows:

$$
\mathbf{D}^{p}=\dot{\lambda} \mathbf{V}_{\Sigma}
$$

such as $\dot{\lambda}$ represents the plastic multiplier, and $\mathbf{V}_{\Sigma}=\partial \Phi / \partial \boldsymbol{\Sigma}$ is the flow direction tensor. By injecting Eq. 4 into Eq. 3, one obtains the rate of equivalent microscopic stress given by the following relation:

$$
\dot{\bar{\sigma}}=\frac{d \bar{\sigma}}{d \bar{\varepsilon}^{p}} \dot{\bar{\varepsilon}}^{p}=H_{\bar{\sigma}} \frac{\Sigma: \mathbf{V}_{\Sigma}}{(1-f) \bar{\sigma}} \dot{\lambda}
$$

Before coalescence, the evolution of porosity is mainly due to two phenomena: nucleation and growth. It is thus possible to express the porosity rate as follows:

$$
\dot{f}=\dot{f}_{n}+\dot{f}_{g}
$$

where $\dot{f}_{n}$ and $\dot{f}_{g}$ represent the porosity rate due to nucleation and growth, respectively. In this work, it is considered that nucleation is strain controlled; in this case the evolution law of $\dot{f}_{n}$ is given by the following relation:

$$
\dot{f}_{n}=A_{n} \dot{\bar{\varepsilon}}^{p}=\frac{f_{N}}{s_{N} \sqrt{2 \pi}} \exp \left[-\frac{1}{2}\left(\frac{\bar{\varepsilon}^{p}-\varepsilon_{N}}{s_{N}}\right)^{2}\right] \dot{\bar{\varepsilon}}^{p},
$$

where $f_{N}$ represents the volume fraction of inclusions likely to nucleate, $\varepsilon_{N}$ the equivalent plastic strain for which half of inclusions have nucleated and $s_{N}$ the standard deviation on $\varepsilon_{N}$. The porosity rate due to growth depends strongly on the stress triaxiality and is given by the following relation:

$$
\dot{f}_{g}=(1-f) \mathbf{D}^{p}: \mathbf{I} \text {. }
$$


The detection of coalescence stage uses the phenomenological criterion introduced by Needleman and Tvergaard [3], by means of the effective porosity such as:

$$
f^{*}=f_{c r}+\delta_{G T N}\left(f-f_{c r}\right) \text {, }
$$

where $f_{c r}$ represents the critical porosity and $\delta_{G T N}$ an acceleration parameter. The use of an implicit finite element program implies necessarily to update at each loading increment the stress field, the set of internal variables and the elasto-plastic tangent modulus. Following Sánchez et al. [5] (see also [6]) the latter quantity is given by the following relation:

$$
\mathbf{C}^{e p}=\mathbf{C}^{e}-\alpha \frac{\left(\mathbf{C}^{e}: \mathbf{V}_{\Sigma}\right) \otimes\left(\mathbf{V}_{\Sigma}: \mathbf{C}^{e}\right)}{H_{\lambda}},
$$

such as:

$$
H_{\lambda}=\mathbf{V}_{\Sigma}: \mathbf{C}^{e}: \mathbf{V}_{\Sigma}-\left(V_{\bar{\sigma}} H_{\bar{\sigma}}+V_{f^{*}} \delta_{G T N} A_{n}\right) \frac{\boldsymbol{\Sigma}: \mathbf{V}_{\Sigma}}{(1-f) \bar{\sigma}}-(1-f) V_{f^{*}} \delta_{G T N} \mathbf{V}_{\Sigma}: \mathbf{I}
$$

where $V_{\bar{\sigma}}=\partial \Phi / \partial \bar{\sigma}, V_{f^{*}}=\partial \Phi / \partial f^{*}$ and $\alpha=0$ for elastic loading or unloading and $\alpha=1$ in case of strict elasto-plastic loading.

\section{Instability criterion}

In addition to the constitutive model, prediction of forming limits requires the use of an instability criterion allowing detection of shear bands. The instability criterion selected in this work is the Rice localization criterion [4], based on the singularity of the acoustic tensor. This instability indicator can be derived from the Hadamard compatibility condition and the static equilibrium equation and is given by the following relation:

$$
\operatorname{det}(\mathbf{Q})=\operatorname{det}(\overrightarrow{\mathrm{n}} \cdot \mathbf{L} \cdot \overrightarrow{\mathrm{n}})=0,
$$

where $\mathbf{Q}$ represents the so-called acoustic tensor, $\vec{n}$ the normal to the localization band and $\mathbf{L}$ the tangent modulus, which relates the nominal stress rate tensor to the velocity gradient (see e.g. Haddag et al. [7]). Its expression is given by the following relation:

$$
\mathbf{L}=\mathbf{C}^{e p}+\mathbf{L}_{1}-\mathbf{L}_{2}-\mathbf{L}_{3}
$$

where $L_{1 i j k l}=\sigma_{i j} \delta_{k l}, L_{2 i j k l}=\left[\delta_{i k} \sigma_{l j}+\delta_{i l} \sigma_{k j}\right] / 2$ and $L_{3 i j k l}=\left[\sigma_{i k} \delta_{l j}-\sigma_{i l} \delta_{j k}\right] / 2$ are fourth-order tensors induced by the large strain formulation, which will be designated as the convective terms in what follows.

\section{Results and discussion}

In what precedes, the coupling of the GTN model to Rice's localization criterion was briefly described. In this section, some results obtained by means of this coupling are illustrated. The studied material corresponds to an Aluminum alloy AA5182. The parameters related to this material were drawn from literature and are reported in the following tables (see Brunet et al. [8] for more details on the material): 
Table 1: Mechanical properties and Swift hardening law parameters

\begin{tabular}{cccccc} 
Material & $E[\mathrm{MPa}]$ & $v$ & $k[\mathrm{MPa}]$ & $\varepsilon_{0}$ & $n$ \\
\hline AA5182 & 70000 & 0.33 & 371.2 & $3.24 \times 10^{-3}$ & 0.17 \\
\hline
\end{tabular}

Table 2: GTN damage model parameters

\begin{tabular}{cccccccccc} 
Material & $f_{0}$ & $s_{N}$ & $\varepsilon_{N}$ & $f_{N}$ & $f_{c r}$ & $\delta_{G T N}$ & $q_{1}$ & $q_{2}$ & $q_{3}$ \\
\hline AA5182 & $10^{-3}$ & 0.1 & 0.27 & 0.035 & 0.00213 & 10 & 1.52 & 1.0 & 2.15
\end{tabular}

Fig. 1.a illustrates the effect of the convective terms $\left(\mathbf{L}_{1}, \mathbf{L}_{2}\right.$ and $\mathbf{L}_{3}$ in Eq. 13) on the prediction of FLDs, and it appears that this effect is negligibly small in the case of the AA5182 material. Thus, in this case the considered instability indicator reduces to the one obtained under small strain hypothesis (i.e. considering the Cauchy stress rate in the static rate equilibrium equation).

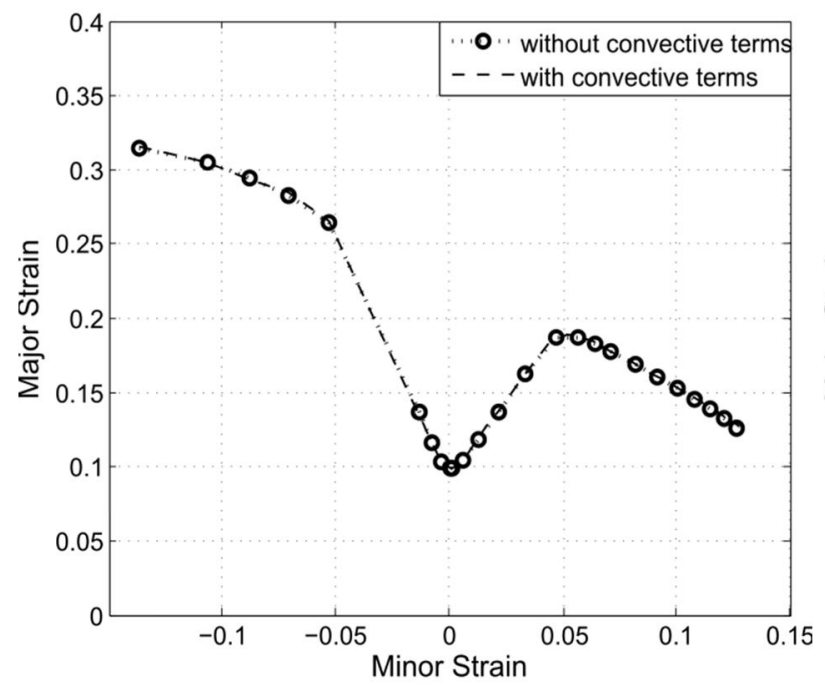

(a)

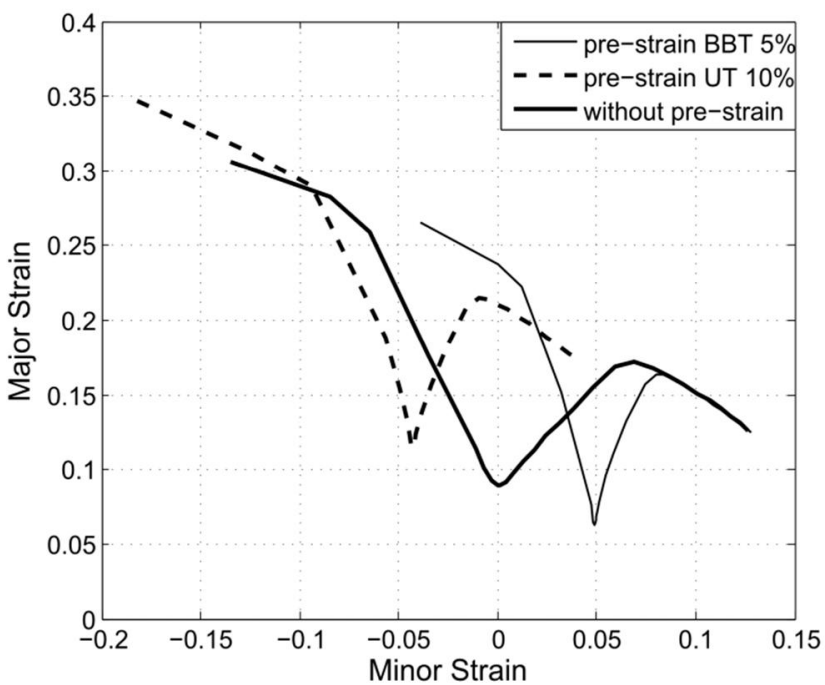

(b)

Figure 1 : Predicted FLD with the proposed approach for the AA5182 material; (a) effect of convective terms; (b) effect of uniaxial tensile (UT) and balanced biaxial (BBT) pre-strains.

Strain-path change effect has been studied by several authors showing the strong dependency of strain based FLDs on non linear loading paths. Figure 1.b illustrates two FLDs obtained with a 5\% balanced biaxial tension (BBT) and a $10 \%$ uniaxial tension (UT) pre-strain along with the one obtained without pre-deformation. One can note that strain-path dependency obtained by experiments is well recovered, where the translation of the FLD to the left is observed when applying a uniaxial tensile strain, whereas for the balanced biaxial loading, the FLD translates to the right.

\section{Effect of hardening parameters}

The GTN damage parameters have an important impact on the occurrence of localization; it was shown that increasing the acceleration term $\delta_{G T N}$ (see Eq. 9) tends to promote plastic strain instability [6]. More generally, the onset of coalescence and the behavior of the material during the softening regime have a major impact on the predicted FLDs. In the current work, we pursue this study by analyzing the effect of hardening parameters (see Table 1). Figs. 2.a, 2.c and 2.e represent the evolution of the Cauchy stress versus true strain up to the localization point for three loading 


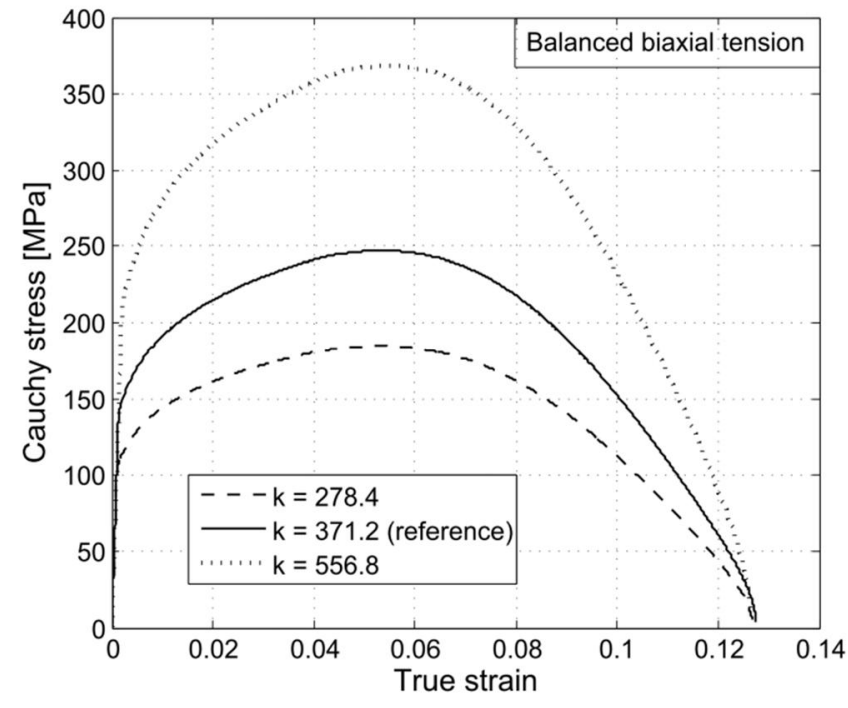

(a)

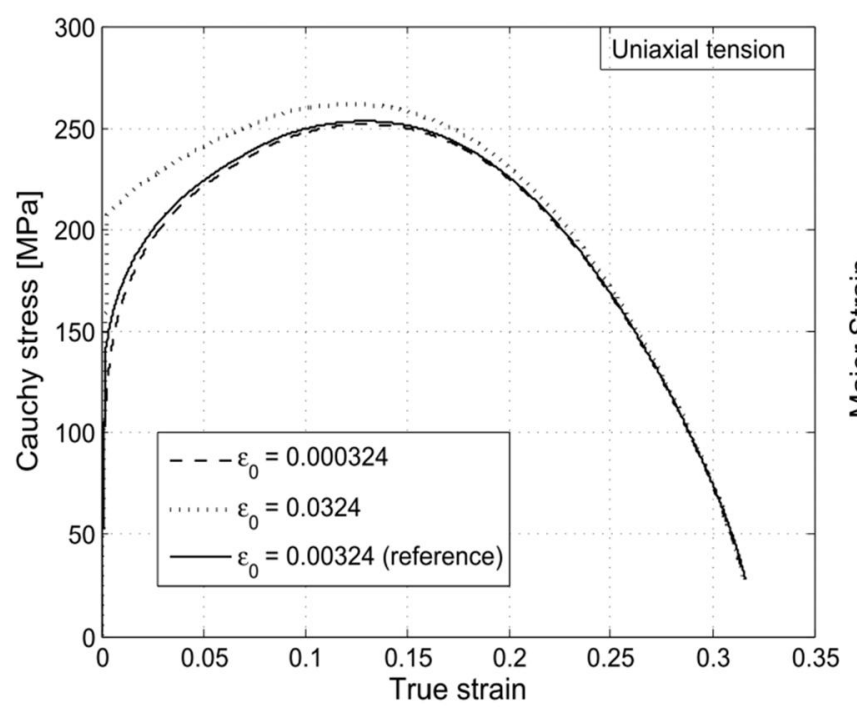

(c)

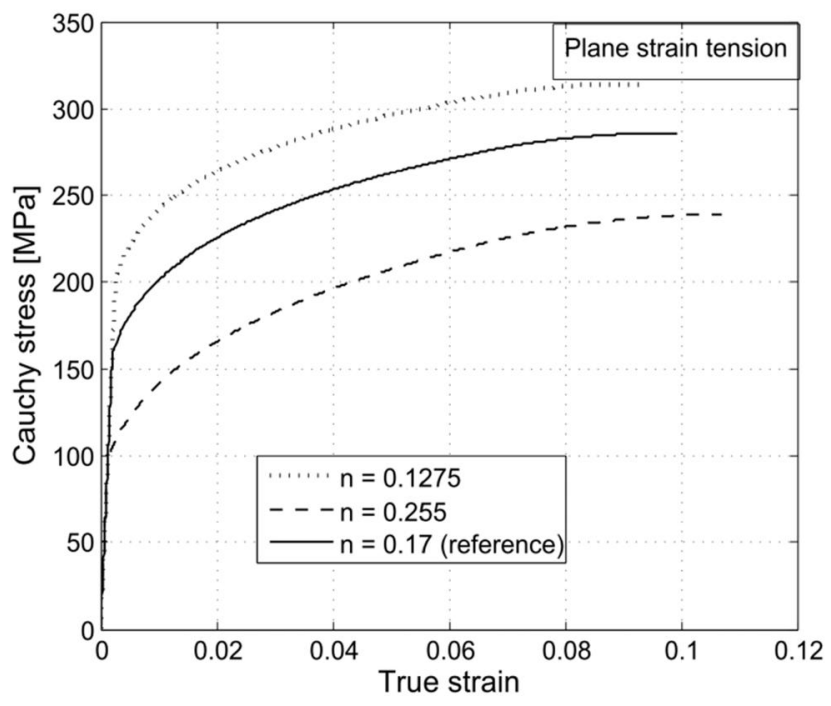

(e)

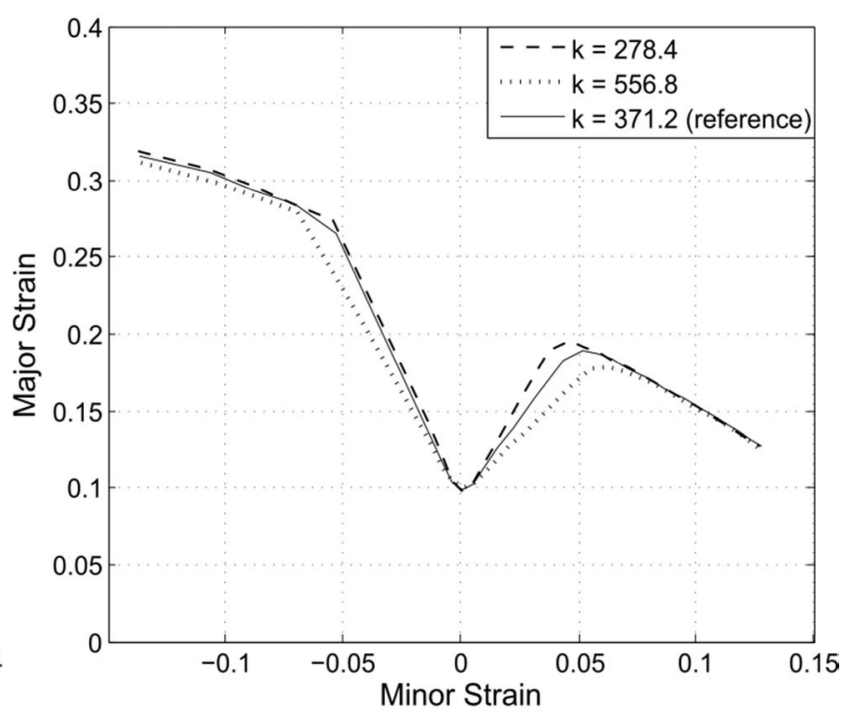

(b)

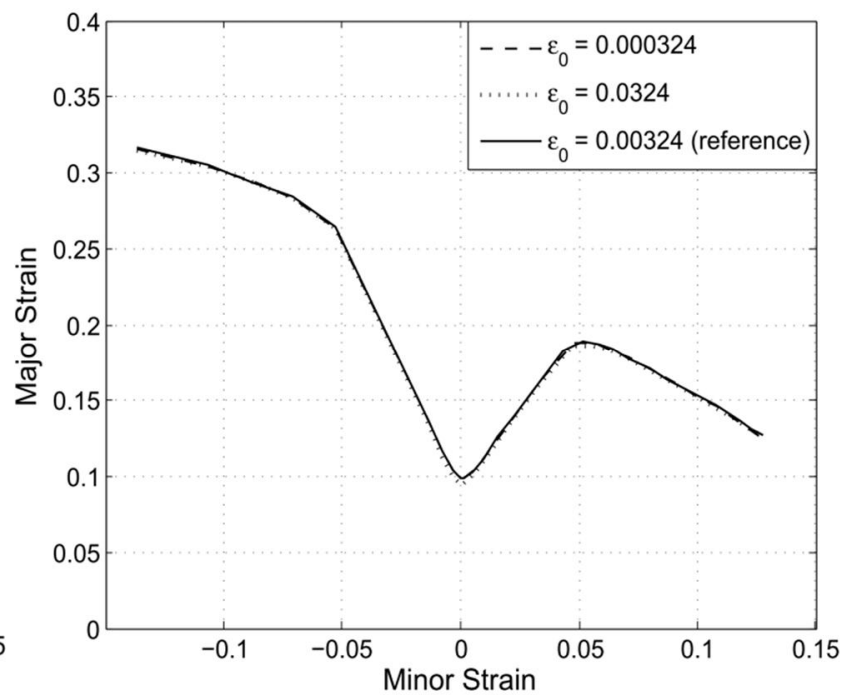

(d)

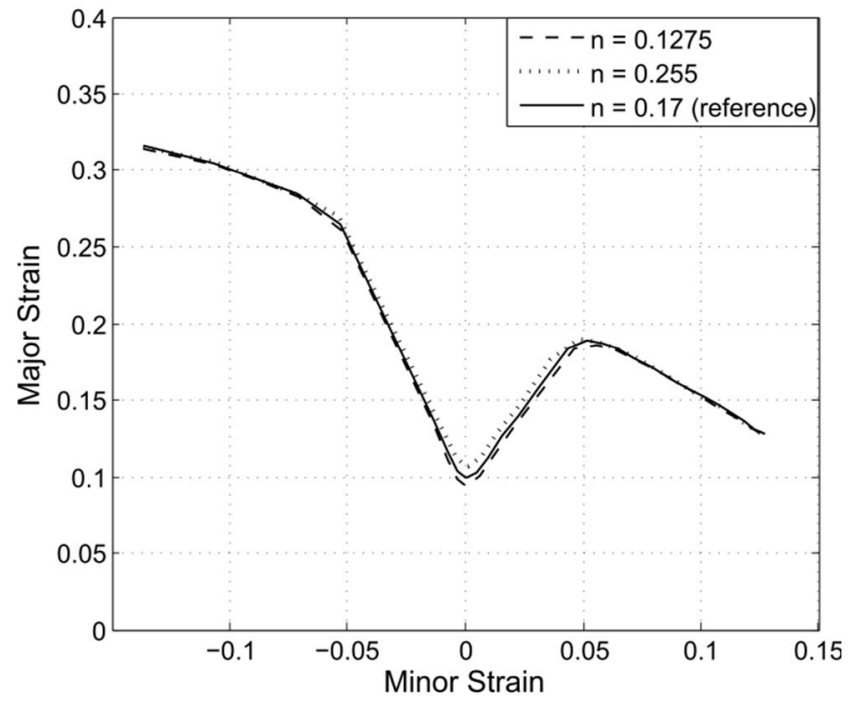

(f)

Figure 2: Effect of the Swift hardening law parameters on the prediction of FLDs by means of the GTN-Rice modeling. 
paths, namely balanced biaxial tension (BBT), uniaxial tension (UT) and plane strain tension (PST). Figs. 2.b, 2.d and 2.f illustrate the effect of hardening parameters on the predicted FLDs. Although for other localization criteria, as the Marciniak and Kuczyński [9] approach or the modified maximum force criterion (Hora et al. [10]), hardening parameters have a major effect on the predicted FLDs, here for the case of the GTN-Rice modeling, it seems that this effect is much smaller.

\section{Conclusion}

In this work, a GTN model has been coupled to Rice's localization criterion for the prediction of forming limit diagrams. This modeling approach was applied to an Aluminum alloy. The GTN-Rice modeling was able to reproduce the strain-path dependence of a strain based FLD. The effect of convective terms can be neglected for this material, and the resulting GTN-Rice coupling appears to be more sensitive to damage parameters related to the softening regime as compared to the hardening parameters.

\section{References}

[1] S.P. Keeler, Determination of the forming limits in automotive stamping, Sheet Metal Ind., 42 (1965) 683-703.

[2] A.L. Gurson, Continuum theory of ductile rupture by void nucleation and growth: Part I-yield criteria and flow rules for porous ductile media, J. of Eng. Mat. and Tech., 99 (1977) 2-15.

[3] A. Needleman, V. Tvergaard, An analysis of ductile rupture in notched bars, J. of the Mech. and Phys. of Solids, 32 (1984) 461-490.

[4] J.R. Rice, The Localization of plastic deformation, in: W.T. Koiter (Eds), Theoretical and Applied Mechanics, Delft, 1 (1976) 207-220.

[5] P.J. Sànchez, A.E. Huespe, J. Oliver, On some topics for the numerical simulation of ductile fracture. Int. J. of Plast., 24 (2008) 1008-1038.

[6] L.Z. Mansouri, H. Chalal, F. Abed-Meraim, T. Balan, Prediction of strain localization during sheet metal forming using bifurcation analysis and Gurson-type damage, XI Int. Conf. on Comp. Plast., E. Oñate and D.R.J. Owen (eds), (2011).

[7] B. Haddag, F. Abed-Meraim, T. Balan, Strain localization analysis using a large deformation anisotropic elastic-plastic model coupled with damage, Int. J. of Plast., 25 (2009) 1970-1996.

[8] M. Brunet, S. Mguil, F. Morestin, Analytical and experimental studies of necking in sheet metal forming processes. J. of Mat. Proc. Tech., 80-81 (1998) 40-46.

[9] Z. Marciniak, K. Kuczyński, Limit strains in the process of stretch forming sheet metal, Int. J. Mech. Sci., 9 (1967) 609-620.

[10] P. Hora, L. Tong, J. Reissner, A prediction method for ductile sheet metal failure, In: Proceedings of the Numisheet'96, (1996) 252-256. 